\title{
Vermelho da cor do sangue, azul da cor do céu
}

Juliana Santos ${ }^{1}$

Jane Tutikian, nascida em Porto Alegre, em 5 de maio de 1952, além de ser professora do Instituto de Letras da Universidade Federal do Rio Grande do Sul desde 1991, desenvolveu sua trajetória como escritora desde a década de 1970. Em 1974, publicou seu primeiro texto, "Batalha naval", no Caderno de Sábado do Correio do Povo, jornal do qual passou a ser colaboradora. Dez anos depois, em 1984, foi lançado seu primeiro livro de maior destaque, A cor do azul, que recebeu Menção Honrosa da Fundação Nacional do Livro Infantil e Juvenil e o Prêmio Jabuti da Câmara Brasileira do Livro. De lá para cá, sua produção de narrativas, tanto para o público adulto quanto para o infantojuvenil, continuou a crescer. E o reconhecimento também, já que foi vencedora de inúmeros prêmios literários, tendo sido escolhida, em 2011, como Patrona da Feira do Livro de Porto Alegre. ${ }^{2}$

Olhos azuis coração vermelho, narrativa infantojuvenil lançada em 2005 pela editora Artes e Ofícios, de Porto Alegre, trata de um tema delicado e raro na literatura brasileira, e não somente nela: a síndrome de Down. Basta lembrar que $O$ filho eterno, de Cristóvão Tezza, obra sensível e referencial nessa temática, foi lançada somente dois anos após a publicação dessa narrativa. Mas se, na obra de Tezza, acompanhamos o amadurecimento do pai e sua trajetória rumo à aceitação do filho, na de Tutikian, seguimos o processo de formação de uma garota que aprende a lidar com seus sentimentos em relação à irmã menor e assim consegue restabelecer seu espaço na família e na vida.

O termo Bildungsroman, ou romance de formação, ${ }^{3}$ foi utilizado, possivelmente pela primeira vez, por Karl Morgenstern em uma conferência

\footnotetext{
${ }^{1}$ Doutora em literaturas brasileira, portuguesa e luso-africanas e professora do Curso de Letras da Faculdade Porto-Alegrense (Fapa), Porto Alegre, RS, Brasil. (Dorcid.org/0000-0002-05870529. E-mail: judinamene@uol.com.br

${ }^{2}$ Os dados biográficos da autora foram extraídos principalmente de seu site pessoal. Disponível em: <janetutikian.com.br>.

3 Cabe frisar que os termos "romance de desenvolvimento" e "romance de educação" são encontrados como sinônimos de "romance de formação", embora seja possível apontar especificidades relativas a esses termos. A pesquisadora Wilma Patricia Maas (2000), que analisou a evolução do Bildungsroman na história da literatura, aprofunda a discussão sobre esses conceitos e sobre sua trajetória no âmbito da crítica literária. Entwicklungsroman (romance de
} 
no ano de 1810, para designar uma "forma de romance que representa a formação do protagonista em seu início e trajetória até alcançar um certo grau de perfectibilidade", promovendo também "a formação do leitor, de uma maneira mais ampla do que qualquer outro tipo de romance". Tal conceito vinha associado ao romance de Goethe intitulado Os anos de aprendizado de Wilhelm Meister (1795-1796), que passou a ser visto como paradigma para o gênero (Maas, 2000, p. 19-20). O romance de Goethe, que depois tem sua continuidade em Os anos de peregrinação de Wilhelm Meister (1821-1829), está bastante vinculado ao contexto alemão do final do século XVIII, já que o conceito de formação na obra diz respeito aos anseios do jovem Wilhelm, que busca o autoaperfeiçoamento e seu lugar no mundo ao mesmo tempo que espelha "o desejo burguês pela formação universal, pelo conhecimento que ultrapassa os limites estreitos da educação para o trabalho e para a perpetuação do capital herdado" (Maas, 2000, p. 20). Desse romance paradigmático do gênero até a produção atual, a percepção sobre o conceito de formação e de Bildungsroman foi sofrendo modificações, inclusive, distanciando-se bastante de seu modelo, mas algumas particularidades ainda norteiam o gênero e, como veremos a seguir, seus traços ainda podem ser percebidos na narrativa em análise.

François Jost, em "La tradition du Bildungsroman", apresenta algumas das principais características desse gênero de narrativa. ${ }^{4}$ Para o crítico (1969, p. 99, tradução nossa), "no romance de aventuras, os acontecimentos afetam e envelhecem o herói", enquanto, no romance de formação, "eles o marcam, o formam de uma maneira definitiva, cristalizam seu caráter". $\mathrm{O}$ confronto do protagonista com os acontecimentos e com o mundo adquire uma função diferente no Bildungsroman:

O mundo não é mais o arsenal de golpes do destino; é uma arena, um terreno de exercício onde o homem se fortalece contra os reveses da fortuna, os riscos da vida. Em vez de sofrer seu destino, o herói se prepara para o afrontar. Em um sentido, o Bildungsroman

desenvolvimento) pode ser entendido como "categoria geral e supra-histórica, a partir do qual se teria desenvolvido a categoria historicamente localizada e datada do Bildungsroman", enquanto Erziehungsroman (romance de educação) está associado a "obras de cunho pronunciadamente pedagógico, nos quais a intervenção de instituições ou de mentores se faça sentir pela realização efetiva de um programa pedagógico" (Maas, 2000, p. 49 e 52).

${ }^{4}$ Já apresentei, de forma mais ampliada, essas características em capítulo de minha tese de doutorado, intitulada Fiç̧ão e crítica de Lucia Miguel Pereira: a literatura como formação, defendida em 2012 na Universidade Federal do Rio Grande do Sul. 
é então apenas uma espécie de pré-romance, de preâmbulo. De fato, ao final da obra, o herói aparece armado para a existência, prestes a viver seu romance (Jost, 1969, p. 99, tradução nossa).

Ao lado desse caráter de "pré-romance", de "preâmbulo", outras características do romance de formação são destacadas, entre elas: a tendência a se retratar a adolescência ou o início da maturidade do homem, "época, precisamente, durante a qual o homem se forma"; a presença constante de um "desenlace feliz ou, ao menos, não implicando, em si, irreparáveis desgraças", de forma que jamais a morte se apresentaria para o protagonista, já que isso o impediria fatalmente de alcançar seu objetivo de formação e o romance perderia sua razão de ser; e, ainda, a tendência de se apresentar como uma narrativa de "final aberto", na medida em que, com a conclusão do romance, uma nova existência se abriria ao protagonista (Jost, 1969, p. 99-103, tradução nossa).

Tais características expressam o que os leitores encontram em Olhos azuis coração vermelho. Ainda que nessa narrativa a formação intelectual da protagonista, aspecto importante na origem do modelo de Bildungsroman, não seja o ponto central da discussão, estamos diante da representação de um processo de formação, voltado especialmente para o amadurecimento psíquico e também social, já que a personagem atinge um novo status ao superar o estágio da infância. Nessa narrativa breve, mas de questionamentos profundos, acompanhamos as primeiras experiências de alguém que se prepara para ingressar na vida adulta, mas que enfrenta, além das inúmeras dificuldades relacionadas a esse período de transição, a dificuldade em aceitar a irmã e um Deus que "deixa que [as crianças] fiquem doentes sem nem saber nem nada que estão doentes" (Tutikian, 2005, p. 69).

Júlia tem 13 anos, é um "espicho ruivo, sardento e sem graça nenhuma" (Tutikian, 2005, p. 46), que está às voltas com suas colegas, seu amor não declarado por Bronco e seu conflito com Titi, a irmã menor, por quem sente um misto de ciúme, raiva e vergonha. $\mathrm{O}$ fato de Titi ser a caçula e de invadir seu espaço com as amigas já seriam motivos suficientes para despertar tais sentimentos, mas há uma razão maior para essa resistência nos "últimos sete anos" (Tutikian, 2005, p. 42):

Aquele nenê que, depois, foi ficando uma criança feia, de olhos azuis puxados, que demorava em fazer tudo, para andar, para falar e que vivia babada e resmungando alto um monte de coisas incompreensíveis e, de repente, ria por nada e chorava por nada, 
aquele nenê sem nenhuma graça ficou sendo o dono do meu pai e da minha mãe (Tutikian, 2005, p. 26).

Cristina, ou Titi, como foi "batizada" pela irmã mais velha, nasceu com síndrome de Down, e "Zulia" não consegue aceitar isso. É a própria narradora que nos informa sobre a expectativa que ela e Cauê, o irmão mais velho, estavam quando souberam da "famosa história da sementinha" e aguardaram pela chegada do "nenê-flor", mas também relata a decepção quando viu que "era um nenezinho bem bem pequenininho! E... feinho" (Tutikian, 2005, p. 24-25). As coisas mudam com a chegada daquele nenê que lhe rouba os pais e que agora ainda lhe envergonha diante das amigas e de Bronco. Ela percebe que o irmão parece não se importar com as coisas que Titi faz. Mais que isso, "na verdade, o Cauê sempre cuidou dela. Ele sempre gostou dela", e confessa: "Está bem. Não é que eu não goste, não goste, às vezes tenho ciúme, quando ela é o centro das atenções, às vezes tenho vergonha dela e, desde ontem, tenho vergonha de mim" (Tutikian, 2005, p. 28).

O psicanalista Otávio Augusto Winck Nunes, no artigo "Ser o mano!", resgata a discussão de Lacan, apresentada em Os complexos familiares, de 1938, especialmente o conceito de complexo de intrusão, para problematizar as relações fraternas e seus conflitos. Reflete sobre a expectativa que existe no imaginário familiar de que irmãos, e particularmente gêmeos, tenham relações marcadas pela amizade, pela ausência de conflito e mesmo de identificação completa, mas reforça que "essa não parece ser a característica das relações fraternas, pelo menos de um bom número delas". Para o autor, nem a consanguinidade, nem o nome de família conseguem "garantir a inexistência de diferenças brutais nas relações humanas, pois elas precisam de uma costura que garanta a manutenção dos laços, permitindo a aproximação, sem fusão, e o afastamento sem ruptura" (2009, p. 106-107, grifo do autor).

A partir disso, percebe-se que a rivalidade e o ciúme em relação ao irmão "intruso" fazem parte desse processo e, no caso de Júlia, temos um aspecto que torna tudo mais complexo: sua irmã caçula exige ainda mais o tempo dos pais e, além disso, é preciso aceitar que essa menina, tão estranha para ela, seja vista como alguém que também carrega seu sobrenome e seu sangue.

Júlia, que admitiu sentir vergonha da irmã, confessa agora que, desde ontem, passou a sentir vergonha de si, e esse novo sentimento está atrelado a um momento-chave em sua vida, e de toda mulher: 
Hoje eu não fui à aula. Minha mãe me deixou ficar em casa porque estava sentindo cólica.

Cólica, eu?

Eu. Na verdade, era tudo tão novo, como as coisas que se sabe que vão acontecer um dia, mas um dia e não com a gente. Talvez por isso o fio fino e vermelho que havia riscado minha perna, quando levantei, me fazia sentir outras coisas que, embora não doessem, eram muito mais fortes do que a cólica (Tutikian, 2005, p. 11).

Olhos azuis se inicia com esse momento simbólico na vida de Júlia, nossa narradora-protagonista, e, de certa forma, o sangue presente na cena inicial associa os dois principais aspectos da narrativa: a puberdade de Júlia e a sua relação com a irmã caçula. A primeira menstruação e com ela o fato de ter se tornado "uma mocinha" despertam a necessidade de voltar-se para si mesma e enfrentar algumas perguntas com as quais tem dificuldade de lidar, especialmente com relação a Titi.

É significativo o fato desse momento de transição para a maturidade, revelado pela presença do sangue, despertar a consciência de Júlia para a relação com a irmã, antes mesmo de lembrar-se de suas dificuldades amorosas em relação à Bronco, mas essas duas facetas de sua vida aparecem interligadas desde o princípio de sua narração:

Talvez eu - e o que conhecia de mim - ainda não estivesse pronta! Achava que, quando isso acontecesse, teria todas as respostas para a minha montanha de perguntas e.

Não tinha nenhuma.

Por que será que o por quê? fica ocupando a vida da gente o tempo inteiro? Por que eu não conseguia fazer a Titi feliz, e fazer o Bronco feliz e me fazer feliz? (Tutikian, 2005, p. 11-12).

Em Os ritos de passagem, Arnold van Gennep (1977, p. 71) destaca que "nas moças a puberdade física é marcada [...] sobretudo pelo primeiro fluxo menstrual", mas, apesar de acentuar a ideia de que "a primeira vez é que tem valor" (Gennep, 1977, p. 147), conforme prega um dito popular, o pesquisador reforça que, se parece "simples datar esse momento de passagem da infância à adolescência", "na realidade as coisas passam-se de modo inteiramente diferente na vida social" (Gennep, 1977, p. 70-71) e destaca fatores como a variação de idade no momento em que isso acontece com cada indivíduo e também o descompasso em relação à descoberta do prazer sexual. 
O livro de Tutikian nos faz acompanhar o processo de iniciação de Júlia para a condição de mulher, quando deixa a infância para trás e ingressa de fato na adolescência. Acompanhamos o primeiro sinal físico de sua puberdade, os rituais associados a ele, mas, principalmente, o processo interno vivenciado pela protagonista, que vai cristalizar essa mudança de estado, de consciência de sua maturidade física e psicológica, o que, na narrativa, se dá ao final daquela semana, período que se associa ao do próprio ciclo menstrual. Nessa transição, além de experimentar os primeiros contatos do amor físico, Júlia consegue ultrapassar o ciúme que sente por Titi e o sentimento de rejeição pela condição da irmã.

Mircea Eliade, filósofo dedicado à pesquisa das religiões, destaca que "o rito de passagem por excelência é representado pelo início da puberdade, a passagem de uma faixa de idade a outra (da infância ou adolescência à juventude)" (Eliade, 2001, p. 150), e também que a iniciação feminina começa com a primeira menstruação (Eliade, 2001, p. 157). Para Eliade,

compreende-se geralmente por iniciação um conjunto de ritos e de ensinamentos orais, que procuram realizar a modificação radical do estatuto religioso ${ }^{5}$ e social do sujeito a ser iniciado. Filosoficamente falando, a iniciação equivale a uma mutação ontológica do regime existencial. Ao final das suas provas, o iniciante goza de uma outra existência, diferente da anterior à iniciação: ele tornou-se um outro (1959, p. 12, tradução nossa).

Ao tratar do conceito de iniciação, Marcel Brion (1977) destaca a natureza subjetiva desse processo, já que encaminha o sujeito às profundezas de seu próprio ser. Afirma o autor:

Toda viagem que se opera no tempo ou no espaço, que leva o indivíduo ao ponto mais profundo dele mesmo ou que provoca magistralmente as mudanças mais impressionantes é, de maneiras numerosas e diversas, uma iniciação. O progresso da vida, este "progresso do peregrino" que instrui o homem a respeito da natureza do universo e da sua própria natureza, que o conduz ao centro de seu ser, ou o projeta a todos os pontos circundantes de seu futuro, adiciona conhecimento e experiência, modifica e metamorfoseia (Brion, 1977, p. 7, tradução nossa).

${ }^{5}$ É importante destacar que o próprio Eliade chama a atenção para o fato de que "o homem moderno que se sente e se pretende a-religioso carrega ainda toda uma mitologia camuflada e numerosos ritualismos degradados" (2001, p. 166). 
Percebemos, assim, que esse momento de passagem se realiza então tanto na dimensão física e ritual quanto na psíquica ou individuativa, o que nos leva ao conceito de individuação, proposto por Carl Gustav Jung (1984, p. 49):

Individuação significa tornar-se um ser único, na medida em que por "individualidade" entendermos nossa singularidade mais íntima, última e incomparável, significando também que nos tornamos o nosso próprio si-mesmo.

Outro componente importante do conceito da individuação, postulado por Jung, é que "o devir da personalidade, e em particular o processo de transformação contínua de uma individualidade", "vem psiquicamente a constituir-se em referência a uma substância comum ou coletiva", e que "a natureza psíquica individual e a comum ou coletiva" se colocam "em uma relação de mútua inclusão e de recíproca remitência" (Pieri, 2002, p. 255-256).

Essa definição mostra que o processo individuativo se constrói no entrelaçamento fundamental entre o indivíduo e o grupo no qual está inserido, a partir de um movimento remitente de aproximação e distanciamento entre eles. Segundo Léon Bonaventure (1984, p. 11), "toda experiência interior tem que ser mediada pela relação com o outro. Nunca alguém se individualiza sozinho, e a finalidade da individuação não é ficar só; pelo contrário, é estar em relação, cada um a seu modo".

Assim, Júlia experiencia um processo dinâmico, em que procura reconhecer-se como ser independente e como integrante do grupo social do qual participa, especialmente no que diz respeito a seu círculo familiar e seus amigos. Sua primeira menstruação desencadeia uma série de eventos, ritos de passagem, que proporcionam esse processo de reconhecimento do eu, de sua individualidade, e, ao mesmo tempo, vão aproximá-la, de uma forma nova, daqueles que a cercam. Esses ritos aparecem na forma como Júlia é acolhida por seus pais e amigas, dando início a uma série de ações que fazem o acontecimento individual tornar-se algo a ser compartilhado coletivamente. Ao mesmo tempo, essas experiências compartilhadas é que permitem à Júlia encontrar sua individualidade e colocar-se diante de seus conflitos interiores.

No primeiro dia em que o sangue desce, a mãe dá atenção especial para a filha, permite que ela falte à aula porque estava com cólica e trata de espalhar a notícia: conta para a mãe de uma de suas amigas, que conta para a filha, que conta para todas as outras amigas. Júlia recorda as 
palavras da mãe: "Uma mocinha, disse minha mãe me olhando com ternura, uma mocinha de 13 anos, a minha filha!" (Tutikian, 2005, p. 11) e a atitude do pai: "entrou no quarto e me abraçou sem uma palavra. Eu? Fiquei dura. Também não disse nada. Há coisas que se dizem sozinhas, eu me dei conta, mesmo sem falar nem nada" (Tutikian, 2005, p. 13).

Logo as amigas chegam ao apartamento, e Júlia confessa a si mesma que deseja a presença de Titi, para também compartilhar de seu "segredo" e daquele momento tão importante de sua vida - "Era a primeira da turma, pelo menos nisso!" (Tutikian, 2005, p. 13):

Quando a campainha tocou, meu coração deu um pulo. Mas. Eram só a Adri, a Suzi, a Cau e a Tuca.

Eu disse só, só porque estava esperando a Titi. Gostava de que elas tivessem chegado, eram minhas melhores amigas do colégio, do prédio e da vida. E foram logo invadindo o quarto, rindo e falando alto, conta pra gente, e sorrisos maliciosos, conta tudo e.

Resolvi fazer mistério:

- Fecha a porta - falei baixinho.

A porta foi fechada, e elas mergulharam na minha cama cheias de curiosidade.

- Bota aí o CPM 22 - a Suzi pediu para a Adri.

$\mathrm{E}$, ao som de Um minuto para o fim do mundo, eu comecei a contar e contei tudo, do sangue do pijama às sensações novas todas, que tinham chegado com ele (Tutikian, 2005, p. 14-15).

As amigas, por iniciativa de Tuca, resolvem deixar uma mensagem na agenda de Júlia, pois "era o meio de guardar aquele tempo, o nosso tempo, para sempre", e ela nos confessa: "Claro que eu não me importava nem nada, eu sabia que aquele era um meu dia-pra-sempre e eu queria poder dividir com elas todos os meus-dias-pra-sempre" (Tutikian, 2005, p. 15).

O livro ainda nos permite ler os recados deixados pelas amigas, apresentados em seu formato "original", e acompanhar a apreciação que Júlia faz das mensagens, percebendo as diferenças e as semelhanças no perfil de suas amigas. Compara-se a Tuca - "a mais parecida comigo, assim, meio encucada com tudo" (Tutikian, 2005, p. 17) -, mas termina por afirmar que todas eram diferentes e viviam "muito bem com isso, ou... talvez por isso" (Tutikian, 2005, p. 18).

Enquanto Júlia ainda está no quarto com elas, Titi “botou a cabeça para dentro do quarto, espiando, como sempre espiava, essa mania que [Júlia] odiava" (Tutikian, 2005, p. 18) e logo foi saindo, como 
costumava fazer - "Eu zá vou indo - e abanou com aquela mão pequena e gorda" (Tutikian, 2005, p. 18) -, já que a irmã sempre a expulsava. Porém, dessa vez, Júlia tem uma nova reação:

Antes que eu, atrapalhada, como sempre, pudesse dizer entra, fica com a gente, a porta fechou. Talvez porque simplesmente fosse difícil dizer que ela entrasse, sem vergonha.

Mas também não sei por quê, nos últimos dias, assim, de uma hora para outra, Titi estava morando na minha cabeça e nem sempre era culpa, não. Era mais uma coisa assim. Uma coisa assim que eu ainda não sabia explicar (Tutikian, 2005, p. 18).

Antes do final desse encontro, as amigas ainda definem que "aquilo merecia uma festa", mas Júlia protesta: "Já não chega a minha mãe anunciando para toda a humanidade?", e então surge a proposta de realizarem a "festa do segredo", quando poderiam compartilhar com todos aquele momento especial, ainda que mantivessem o sigilo sobre a intimidade da amiga - "só nós saberemos por quê" (Tutikian, 2005, p. 19).

A próxima etapa do rito passa então a ser o momento de preparação para a festa, que inclui o encontro para a escolha das roupas e a maquiagem, o que só há pouco haviam começado a fazer. Júlia, novamente, percebe o seu desejo de que Titi participe, mas não está pronta para admitir isso:

Titi estava me espiando.

Tive uma vontade meio boba, meio ridícula, de que ela dissesse que eu estava bonita. De repente me dei conta de que não faria a menor diferença, se ela achasse. Mas também me dei conta de que, não sei por quê, ficaria feliz se ela dissesse.

Para contrariar, não disse. Me olhou com os olhos azuis, puxados, quase escondidos embaixo de uma franja grossa e disse:

- Zá vou indo.

Queria, de novo, queria pedir que ela ficasse, mas um isso dentro de mim - como se eu fosse trair minha vida dos últimos sete anos não me deixava pedir (Tutikian, 2005, p. 41-42).

O irmão parece não tomar conhecimento dos fatos nem participar desses ritos, que tomam mesmo uma configuração de demarcar um território feminino, mas participa da organização da festa do segredo e acaba assumindo o papel de integrar Titi ao evento, quando pede a ela para recortar alguns enfeites para o salão. A menina se alegra, e Júlia percebe que "aquele rosto feio e igual a milhares, talvez milhões, no 
mundo, eu não sei, de alguma maneira, aquele rosto feio era bonito quando estava feliz" (Tutikian, 2005, p. 39), e, mais tarde, quando olha para Titi com purpurina nos cabelos, no rosto, na língua, uma "ideia meio absurda" lhe passa pela cabeça: "será que ela tem alguma coisa de anjo mesmo?" (Tutikian, 2005, p. 39-40).

No decorrer da festa, outros acontecimentos simbólicos integram esse ritual de passagem vivenciado por Júlia: primeiro, a dança com Bronco, e depois, na saída, o beijo. Outros casais voltam juntos para casa, e Júlia observa seu comportamento, as diferenças existentes naquelas relações e, assim, consegue avaliar o que está vivendo com Bronco:

E, então, Bronco passou os braços na minha cintura e me puxou para perto dele e foi chegando, olhando no meu olho, chegando, olhando a minha boca e me beijou.

Não!

N-Ó-S nos beijamos. [...]

Depois, veio o silêncio, como se estivéssemos tentando entender isso. E estávamos (Tutikian, 2005, p. 52).

O olhar dele sobre ela a faz perceber o próprio corpo e também o próprio desejo, que se efetiva na realização do beijo. $O$ silêncio instaurado entre eles, ao mesmo tempo que os individualiza, integraos naquela experiência em comum. E é somente à noite, no quarto de Suzi, onde todas dormem naquele dia, que Júlia verbaliza tudo o que viveu naquela noite e, através desse ato, toma consciência disso: "me surpreendi com o jeito bonito que contei e, mais ainda, porque eu tinha contado a verdade e a verdade estava ficando como um sonho meio mágico, maior do que eu tinha pensado, maior do que eu" (Tutikian, 2005, p. 56). As amigas também compartilham suas histórias de amor, relatando inclusive experiências de seus pais e avós, e, naquela noite, o grupo experimenta o primeiro conflito relacionado ao amor: Tuca e Suzi discutem por causa de Cauê, o irmão de Júlia, e ela percebe que agora "já tinha passado o tempo em que [ficavam] bem com amores à distância" (Tutikian, 2005, p. 54-55).

Quando acordam, Júlia sente "um daqueles ataques", que tem às vezes, "de vontade de ir pra casa" (Tutikian, 2005, p. 63). Deseja ficar sozinha, refletir sobre tudo o que vem acontecendo dentro de si, mas, ao chegar em casa, depara-se com os pais e percebe que o irmão já tinha confidenciado a eles a notícia do seu namoro com Bronco. Júlia, na noite anterior, já havia interiormente desejado a aprovação da mãe: 
Verdade mesmo é que eu queria muito que ela gostasse da notícia, precisava que ela gostasse da notícia, dentro de mim sabia que era uma chance de nos aproximarmos. Queria que ela fosse minha amiga, como a professora Sandra era, para ela eu podia contar tudo, mas. Parecia que a vida da minha mãe se chamava Titi (Tutikian, 2005, p. 59)

A recepção dos pais e do irmão mostra a ela que seu desejo de aceitação pelo grupo familiar se concretiza, e ela consegue essa aproximação desejada com a mãe. Mas ainda lhe falta superar o conflito com Titi. Fica sabendo que a irmã caçula ainda estava dormindo porque havia chorado muito à noite, em razão de sua ausência, então pensa em ir até o quarto, "acordá-la e dizer que estava tudo bem, que podia dormir em paz porque ia ficar ao lado dela. Mas" (Tutikian, 2005, p. 66). Júlia não consegue. Vai para seu quarto e só consegue chorar, mas também percebe algumas razões para essa resistência: "Tinha vergonha de demonstrar carinho. Tinha vergonha em relação às pessoas" (Tutikian, 2005, p. 66), e vai além:

Tinha um isso dentro de mim que me impedia de chegar mais perto da Titi, por ela e, talvez, mais do que isso, porque podia significar, para o meu pai e a minha mãe, que eu aceitava que tudo tivesse sido e fosse como era. Eu não aceitava: eles não gostavam de mim (Tutikian, 2005, p. 66).

O isolamento no quarto é simbólico tanto no sentido de proporcionar esse momento de revelação interior, de amadurecimento da personagem, quanto para o sentido de encerramento das etapas que constituíram seu ritual de passagem, da infância para o começo da vida adulta. Joseph Campbell, em sua obra intitulada O herói de mil faces, afirma que

os chamados ritos [ou rituais] de passagem, que ocupam um lugar tão proeminente na vida de uma sociedade primitiva [...], têm como característica a prática de exercícios formais de rompimento normalmente bastante rigorosos, por meio dos quais a mente é afastada de maneira radical das atitudes, vínculos e padrões de vida típicos do estágio que ficou pra trás. Segue-se a esses exercícios um intervalo de isolamento mais ou menos prolongado, durante o qual são realizados rituais destinados a apresentar, ao aventureiro da vida, as formas e sentimentos apropriados à sua nova condição, de maneira que, quando finalmente tiver chegado o 
momento do seu retorno ao mundo normal, o iniciado esteja tão bem como se tivesse renascido (Campbell, 2003, p. 20-21).

No momento de isolamento, as reflexões sobre Titi tomam outro grau de aprofundamento:

Eu não sabia nem em que mundo nem onde era aquele mundo em que ela vivia. A verdade é que, talvez, jamais chegasse a saber. Tudo o que conseguia perceber é que ela era uma criança alegre, ria com facilidade e demonstrava muito carinho com as pessoas, principalmente com a minha mãe e com o Cauê; com os bichos; as bonecas e.

Não sei por que eu fazia parte dessa lista, quando fazia tudo para não fazer. Muitas e muitas vezes tinha perguntado para o Deus por que ele faz isso com as crianças, por que ele deixa que elas fiquem doentes sem nem saber nem nada que estão doentes, perguntei por que existem bichos abandonados, enquanto outros têm gente para amá-los, perguntei por que os velhos têm que ser velhos como são os velhos, indefesos, se morria de pena quando via um deles comendo. Eram frágeis as crianças como a Titi, os velhos, as crianças e bichos abandonados. Se ele via, como eu via, e eu nunca podia ver mais do que ele, por que deixava que fossem assim? As respostas eram sempre silêncio e eu começava a precisar de palavras. Minha mãe dizia, apenas, que ele escreve certo por linhas tortas.

$\mathrm{Eu}$ ?

Queria que não precisasse ser assim (Tutikian, 2005, p. 69-70).

Ela se permite experimentar a dor, o medo pela fragilidade da irmã (e por si própria, já que seu pensamento também envereda por questões como a velhice e o abandono) e questiona Deus. Também se opõe ao conformismo, ou à fé, que pressente por trás das palavras da mãe. $\mathrm{O}$ "Eu", aqui posto em cheque pela interrogação ("?"), ensaia dar uma outra resposta ao problema, a sua resposta: "Queria que não precisasse ser assim".

Passado esse momento de reclusão, a mãe de Júlia obriga a filha mais velha a levar Titi a um chá na escola, realizado para comemorar o dia do amigo. Fica furiosa e envergonhada, porque sabia que a banda do irmão, que incluía Bronco, tocaria na festa, e ela estaria lá diante do novo namorado naquela situação embaraçosa. A realidade concretiza os seus temores: 
Os meninos estavam tocando e a Titi cantava, ou melhor, gritava e batia palmas do jeito que sabia. Cauê e Bronco, do palco, a incentivavam. Pensei em mandá-la parar com aquilo, porque estava me envergonhando, mas, então, olhei para trás e vi um outro mundo, havia dezenas de Titis, uns maiores, outros menores. Os mesmos olhos puxados, escuros e claros, o mesmo jeito de falar e de cantar. As mesmas palmas. A mesma alegria.

Meu coração começou a bater muito depressa, a respiração ficou difícil. Minha primeira reação foi de correr, de fugir, de fechar os olhos, mas. Alguma coisa maior do que eu me fez ficar.

Adri perguntou o que eu tinha, que estava tão branca. Respondi que nada, que estava tudo bem. E aquelas dezenas de Titis, meninos e meninas, cantando e batendo palmas. Vozes e mãos desencontradas (Tutikian, 2005, p. 75-76).

A maneira como Cauê e Bronco tratam a menina nessa festa, e em outras situações ao longo da narrativa, de certa forma, serve de exemplo para Júlia, o que nos faz pensar no papel que eles assumem nesse momento de mudança, de formação do seu caráter. Também é recorrente, entre as características do romance de formação, a presença de mentores, que, através da orientação ou do exemplo, auxiliam no processo de constituição de valores do sujeito, papel que os dois personagens parecem sutilmente assumir, na medida em que servem como um modelo nas suas formas de aceitar Titi e de interagir com ela, e esse aprendizado, de certo modo, também é repassado ao leitor. Nesse sentido, a visão de formação humanística presente no século XVIII, e plasmada na obra de Goethe, pode ser repensada no contexto dessa narrativa, na medida em que esta sugere concepções atuais de formação, como a preocupação com a alteridade e a busca por uma educação libertadora e não mais liberal, como no modelo tradicional de Bildungsroman.

Nessa cena, Júlia, para além da sensação de vergonha e desconforto, começa a ter a compreensão de algo maior do que a irmã, do que sua disputa com ela. Enxerga uma realidade diversa da sua, mas com a qual Titi forma uma outra harmonia, e isso se descortina diante de seus olhos (e dos olhos do leitor), ali no palco, no centro da sua atenção e da de todos. Aquilo que era tão estranho e repudiado parece tomar um novo sentido, passa a ser reconhecido em sua alegria, em sua beleza:

A diretora do colégio interrompeu a banda [...]. 
As crianças tomaram o palco. Primeiro cantaram cantigas de roda, depois, uma menina maior disse, ajudada pela professora, uma poesia, depois, ainda, foi a vez de cantarem, cheios de gestos, "Como é grande o meu amor por você". Cada um cantava à sua maneira, eram vozes desafinadas e desencontradas. Bonitas.

Uma bola enorme trancou na minha garganta e eu tentei disfarçar. As pessoas aplaudiram e eles, desengonçados, agradeceram com um gesto exagerado de cabeça. Titi esqueceu-se de agradecer e ria com a mão, babada, na boca babada.

A professora, então, pediu que eles descessem, com cuidado, do palco e entregassem o coração para o seu melhor amigo.

Foi nesta hora que a mãe e o pai chegaram. Eles estavam visivelmente orgulhosos da Titi.

Definitivamente, essa expressão "com cuidado" não existia para eles. Saltaram do palco e correram como uma verdadeira avalanche em direção às mesas.

Eu sabia que a escolhida da Titi seria a minha mãe, e gostava que fosse.

Mas.

De repente, ela parou muito próxima de mim e me deu o coração vermelho, de cartolina e, sem que eu esperasse, passou os braços na minha cintura e encostou o rosto no meu peito e ficou assim.

Pousei a mão no seu rosto e, delicadamente, o acariciei, como nunca tinha feito, e chorei, chorei pelos últimos sete anos, por este lugar que ninguém mais, além de mim, pisou.

Minha mãe, emocionada, passou a mão nos meus cabelos sem dizer nada, e nem precisava.

Como uma ventania, tudo o que havia vivido, tudo o que havia vivido nesta semana me mostrava, finalmente, me mostrava que estava perto de todas as pessoas que amava e, com elas, eu começava a descobrir a vida no que ela tem de recomeço (Tutikian, 2005, p. 76-77).

De fato, a experiência de Júlia é única; aquele "lugar", só ela pisou, e agora consegue examinar, reconhecer, sentir e superar. A entrega simbólica do coração seguida pelas lágrimas da protagonista mostram que o encerramento dessa narrativa é apenas um preâmbulo da história que se seguirá: podemos sentir que ela conseguiu romper com a mágoa e o ciúme vividos nos seus primeiros anos e que uma nova relação entre as irmãs ocorrerá a partir de então. Júlia atinge outro patamar em seu 
processo de amadurecimento e de percepção de sua individualidade e, assim, poderá ser para Titi o que seu irmão mais velho foi para ela: amigo, confidente, conselheiro, protetor. $\mathrm{O}$ vermelho do sangue, símbolo que concentra sentidos como família, dor, puberdade, transmuta-se no vermelho do coração de cartolina. E o azul dos olhos de Titi, que não era percebido em sua beleza, parece agora a promessa de um novo céu, sem nuvens, na existência que se abre para Júlia.

\section{Referências}

BONAVENTURE, Léon (1984). Prefácio. In: VON FRANZ, Marie-Louise. A individuação nos contos de fada. Tradução de Eunice Katunda. São Paulo: Paulus.

BRION, Marcel (1977). L'Allemagne romantique: Le voyage initiatique I. Paris: Albin Michel.

CAMPBELL, Joseph (2003). O herói de mil faces. Tradução de Adail Ubirajara Sobral. São Paulo: Cultrix; Pensamento.

ELIADE, Mircea (1959). Initiation, rites, sociétés secrètes: naissances mystiques. Paris: Gallimard.

ELIADE, Mircea (2001). O sagrado e o profano: a essência das religiões. Tradução de Rogério Fernandes. São Paulo: Martins Fontes.

GENNEP, Arnold van (1977). Os ritos de passagem: estudo sistemático dos ritos da porta e da soleira, da hospitalidade, da adoção, gravidez e parto, nascimento, infância, puberdade, iniciação, coroação, noivado, casamento, funerais, estações, etc. Tradução de Mariano Ferreira. Apresentação de Roberto da Matta. Petrópolis: Vozes.

JOST, François (1969). La tradition du Bildungsroman. Comparative Literature, Durham, v. 21, n. 2, p. 97-115.

JUNG, Carl Gustav (1984). O Eu e o inconsciente. Tradução de Dora Ferreira da Silva. Petrópolis: Vozes.

MAAS, Wilma Patricia (2000). O cânone mínimo: o Bildungsroman na história da literatura. São Paulo: Editora da Unesp.

NUNES, Otávio Augusto Winck (2009). Ser o mano! Revista da Associação Psicanalítica de Porto Alegre, Porto Alegre, n. 37, p. 102-111, jul./dez.

PIERI, Paolo Francesco (2002). Dicionário junguiano. Tradução de Ivo Storniolo. São Paulo: Paulus. 
TUTIKIAN, Jane (2005). Olhos azuis coração vermelho. Porto Alegre: Artes e Ofícios. TUTIKIAN, Jane (2010). Site pessoal. On-line. Disponível em: <janetutikian.com.br>. Acesso em: 28 maio 2017.

Recebido em 20 de junho de 2017.

Aprovado em 9 de janeiro de 2018.

\section{resumo/abstract/resumen}

\section{Vermelho da cor do sangue, azul da cor do céu}

Juliana Santos

Este trabalho apresenta uma proposta de estudo da narrativa infantojuvenil Olhos azuis coração vermelho, de Jane Tutikian (2005), e, a partir de conceitos como individuação, romance de formação e rito de passagem, discute a forma como a narrativa apresenta o processo de amadurecimento da personagem Júlia a partir da relação que estabelece com sua irmã Titi, portadora da síndrome de Down. Considerando os postulados teóricos de Carl Gustav Jung, François Jost, Arnold van Gennep, entre outros, são analisados a trajetória da protagonista em busca de sua identidade e o papel que os conflitos com sua irmã caçula tiveram nesse processo.

Palavras-chave: Olhos azuis coração vermelho, Jane Tutikian, romance de formação, individuação, rito de passagem, síndrome de Down.

\section{Red like blood, blue like the sky}

Juliana Santos

This essay analyzes the children's literature book Olhos azuis coração vermelho [Blue eyes red heart] by Jane Tutikian (2005). Using concepts like individuation, bildungsroman, and rite of passage, the article discusses the manner in which the narrative presents the protagonist's (Julia) development through her relationship with her sister (Titi), who has Down syndrome. Employing theoretical postulates by Carl Gustav Jung, François Jost, Arnold van Gennep, among others, the essay analyzes the protagonist's journey in search of identity and the role that her conflicts with her younger sister play in this process.

Keywords: Olhos Azuis Coração Vermelho, Jane Tutikian, bildungsroman, individuation, rite of passage, Down syndrome. 


\section{Rojo del color de la sangre, celeste del color del cielo}

Juliana Santos

En este trabajo se presenta una propuesta de estudio del relato infantil-juvenil Olhos azuis coração vermelho [Ojos celestes corazón rojo], de Jane Tutikian (2005) y, a partir de conceptos como los de individualización, la novela de formación y el rito de pasaje, se discute la forma en que el relato presenta el proceso de maduración del personaje Júlia a partir de la relación que establece con su hermana Titi, portadora del síndrome de Down. Teniendo en cuenta los postulados teóricos de Carl Gustav Jung, François Jost, Arnold van Gennep, entre otros, se analiza la trayectoria de la protagonista en busca de su identidad y también el papel que tuvieron los conflictos con su hermana menor en ese proceso.

Palabras clave: Olhos azuis coração vermelho, Jane Tutikian, novela de formación, individualización, rito de pasaje, síndrome de Down. 